\title{
REGULATORY GUIDELINES FOR APPROVAL OF BIOSIMILARS IN INDIA, EUROPE, BRAZIL AND CHINA: A COMPREHENSIVE OVERVIEW
}

\author{
MEENAKSHI K. CHAUHAN*, SHIPRA MALIK \\ Delhi Institute of Pharmaceutical Science and Research, Pushp Vihar, Sec-3 New Delhi 110017 \\ Email: meenakshikanwar@yahoo.com
}

Received: 16 Mar 2016 Revised and Accepted: 12 Aug 2016

\section{ABSTRACT}

A biosimilar is a biological medicinal product that contains a version of the active substance of an already authorized original biological medicinal product (reference medicinal product). A biosimilar demonstrates similarity to the reference biological product in terms of quality characteristics, biological activity, safety and efficacy based on a comprehensive comparability exercise. EMA (European Medicines Agency) was the first to introduce the guidelines for biosimilar approval, effective from June 2006. Biosimilar guideline was released in 2010 in Brazil and 2012 in India. Recently China published its guideline for biosimilar approval in 2015.

This article summarizes the regulatory requirements for approval of biosimilars in India, Europe, Brazil, and China. These countries require comparability exercise of a biosimilar with reference biological product for generating comparative analytical, non-clinical and clinical data (usually one or two phase 1 and phase 3 comparative studies). A case study of infliximab biosimilar approval in India, Brazil and Europe has also been included.

\section{Keywords: Brazil, China, Europe, infliximab biosimilar, India}

(C) 2016 The Authors. Published by Innovare Academic Sciences Pvt Ltd. This is an open access article under the CC BY license (http://creativecommons. org/licenses/by/4. 0/) DOI: http://dx.doi.org/10.22159/ijpps.2016v8i10.11753

\section{INTRODUCTION}

European nations are the biggest market for biosimilars, followed by Asia-Pacific countries with, China and India expected to grow at the fastest rate. Brazil is also poised to register high growth rate in next five years [1, 2]. The first opinion on biosimilars was published by the European Union (EU) in early 2000s, post which many guidelines covering individual biosimilars were released and revised from time to time. [3]. Around the same time, the US Food and Drug Administration (FDA) started discussing the concept of so-called "follow-on biologics" [4] with first draft guidance published in February 2012 and updated in 2015. India, Brazil and China and Brazil released their biosimilar guidance in 2010, 2012 and 2015 respectively.

Unlike small chemical molecules, with defined and entirely reproducible structure, proteins are more complex and unlikely to be structurally identical to a reference product. Many potential differences in protein structure can arise. Even minor structural differences (changes in glycosylation patterns) can significantly affect a protein's safety and effectiveness and hence it is important to evaluate these differences [5]

Since biosimilars are not "generic medicines", many characteristics associated with the authorization process do not apply. Manufacturing biosimilars are highly complex and expensive apart from the unique knowledge required to establish the relevant cell clone expressing the protein [5]. The current analytical methodology may not be able to detect all relevant structural and functiona differences between two protein products [6]. Also, there may be an incomplete understanding of the relationship between a product's structural attributes and its clinical performance.

The data derived from analytical studies, animal studies, and clinical studies are required to demonstrate bio-similarity because bioavailability/bioequivalence studies alone would not conclude the bio-similarity is owing to the complex nature of the biotechnologyderived products [5]

Whether the 'biosimilar' approach would be applicable to an individual biological medicinal product depends on the state of the art of analytical procedures, the manufacturing processes employed as well as clinical and regulatory experiences, e. g. as regards the possibility to identify comparability margins, availability of sensitive clinical endpoints and model conditions etc [5]

The posology and route of administration of the biosimilar should be similar to the reference medicinal product. Deviations from the reference product as regards formulation or excipients require justification or further studies [5, 7]

A similar step-by-step development process for biosimilars followed across geographies

The development of a biosimilar involves stepwise comparability exercise(s) beginning with an evaluation of the quality characteristics of biosimilar and reference biological product Establishing similarity between biosimilar and reference biological requires comparison of quality characteristics that will lead to the reduction of non-clinical and clinical data needed for the approval process. If relevant differences are found in the quality, non-clinical or clinical studies, the product will not likely qualify as a biosimilar, and a more extensive non-clinical and clinical data set will likely be required to support its application for licensure. The extent and nature of the non-clinical and clinical studies to be performed depend on the level of evidence obtained in the previous step(s) including the robustness of the physicochemical, biological and nonclinical In vitro data. The goal is to exclude differences between the biosimilar and the reference medicinal product. Therefore, studies should be sensitive enough with regard to design, population, endpoints, and conduct to detect such differences [8]

Step-wise approach

a. Analytical, quality comparison/characterization

- Manufacturing process

- Product characterization

- Structural and physicochemical properties

- Biological activity

- Immunological properties

- Purity and impurities

- Stability 
- Quality comparability study

b. Non-clinical studies (Comparative)

- In vitro studies

- In vivo studies

c. Clinical studies (Comparative)

- Pharmacokinetic (PK) studies

- Pharmacodynamics (PD) studies

- Confirmatory safety and efficacy studies

- Safety and immunogenicity data

Data requirement (including local clinical data)

- Biosimilars need to establish similarity to the reference product in terms of quality, non-clinical and clinical studies.

- Analytical and non-clinical data requirement are similar across countries.

- Local subject participation is required in local or global phase I and phase III study. Local Phase I studies may be waived off in certain geographies at the discretion of the regulatory authority.

- Since local participation is required in all countries, so Phase III trial should be global and multi-centric.

- There is a need to develop a robust post-marketing surveillance plan to allay safety/immunogenicity concerns.

\section{Reference product requirement}

Reference product should be registered in a country where the approval for a biosimilar is sought. Reference product registered in a different country may be used with bridging data comparing biosimilar, country registered reference product and out-site country registered reference product used in comparability exercise.

\section{Clinical trials initiation and filing of biosimilar application}

Clinical trials can be initiated at any time irrespective of patent expiry. This provision is available in many countries and is similar to BOLAR provision in US [§ 271(e) (1) exemption from infringement if patented reference product is used for generating data for submitting to regulatory agency]. Biosimilar application can be filed only after the expiry of regulatory/data exclusivity. In Europe, the application can be filed after eight years of data exclusivity; however, approval can happen after ten years of exclusivity $(8+2$ exclusivity). There is no data exclusivity in India and Brazil.

However, a biosimilar can only be approved or launched after the expiry of patent and regulatory exclusivity. Approval time for biosimilar usually ranges from $12-20 \mathrm{mo}$. To be among the early entrants in the main markets, clinical development of biosimilars should be completed at least two years before the expiry of the patent, taking into consideration time for dossier preparation and regulatory review.

\section{Indication extrapolation}

Extrapolation to other indications is acceptable based on scientific justification. By submitting data for one lead indication, approval for other approved indications (extrapolation) of reference product is possible if scientific justification is provided.

\section{Interchangeability}

No provision of interchangeability in guidelines of most geographies. In EU, no automatic substitution and decision for interchangeability are left to the member state.

India-biosimilar regulatory requirement [9-12]

\section{Guideline}

Regulatory requirements for marketing authorization of similar biologic in India were released in 2012 and require extensive quality/analytical comparative data in addition to abridged clinical/non-clinical studies are required for biosimilar approval.

\section{Data requirement}

\section{Analytical and quality characterization data}

Comparability according to critical quality attributes of product including physicochemical properties, biological activity, immunological properties, functional assays, purity (process and product-related impurities, etc.), contamination, strength, and content.

\section{Non-clinical studies}

- In vitro studies: e. g. cell-based bioassay (e. g., cell proliferation assays or receptor binding assays]

- In vivo studies: PD activity, immunogenicity, at least one repeat dose toxicity study, local tolerance (may be part of repeat dose toxicity study); safety pharmacology, reproductive toxicity, mutagenicity, and carcinogenicity studies are not required unless warranted by repeat dose toxicity studies.

\section{Clinical studies}

- Phase I: Comparative PK (Pharmacokinetics) and PD (pharmacodynamics) studies; PK/PD relationship may be evaluated. PD evaluation can also be done as part of Phase III study (usually 1 or 2 Clinical Trails (CTs) depending on indications)

- Phase III: Comparative efficacy and safety/immunogenicity study are essential (usually 1 or 2 CTs, depending on a number of indications and safety profile).

- Equivalence design study is preferred.

- Non-inferiority design needs to be justified.

- Safety and efficacy CT can be waived off if comparable quality, non-clinical and clinical PK-PD data with post-marketing risk management plan is provided (cannot be waived if there is no reliable and validated PD marker).

- Post-marketing: Safety and immunogenicity data must be submitted

\section{Extrapolation to other indication}

May be possible if the same Mechanism of Action (MOA)/receptors for indications (with similar safety, efficacy, preclinical and quality data)

\section{Reference product requirements}

- Reference biologic should be licensed in India and should be innovator product.

- If reference biologic is not marketed in India, then it should be licensed and widely marketed for four years post approval in innovator jurisdiction in a country with the well-established regulatory framework.

- In case no medicine or only palliative therapy is available or in the case of national healthcare emergency, this period of $4 \mathrm{y}$ may be reduced or waived.

\section{Interchangeability}

Not mentioned in the guideline.

\section{Europe-biosimilar regulatory requirement $[3,13-15]$}

\section{Guidelines}

- $\quad$ EU Guideline on similar biological medicinal products

- EU Guideline on similar biological medicinal products containing biotechnology-derived proteins as active substance: quality issues (revision 1)

- EU Guideline on similar biological medicinal products containing biotechnology-derived proteins as active substance: non-clinical and clinical issues

Similar Biological Medicinal product is a biological medicinal product that is similar to the active substance of an already 
authorized biological medicinal product (reference medicinal product) in European Economic Area (EEA). The similarity to reference medicinal product in terms of quality characteristics, biological activity, safety and efficacy based on a comprehensive comparability exercise must be established. Comparative analytical data along with the clinical and non-clinical data is required to establish the similarity.

\section{Data requirement}

\section{Analytical, quality characterization data}

Comprehensive analyses of biosimilar and reference product. Any differences detected in quality attributes will have to be appropriately justified concerning their potential impact on safety and efficacy.

\section{Non-clinical data}

- $\quad$ Phase 1: Comparative PK/PD studies

- Usually 1 or 2 CTs depending on indications

- Phase 3: Confirmatory Safety and Efficacy Studies

- Usually 1 or 2 CTs, depending on a number of indications and safety profile.

- In general, an equivalence design should be used.

- The non-inferiority design may be acceptable if justified on the basis of a strong scientific rationale.

- $\quad$ Post-marketing: Safety and immunogenicity data

\section{Extrapolation to other indication}

- Extrapolation to other indications needs to be scientifically justified

- $\quad$ Additional data required

- If the drug acts on multiple active sites/receptors in different indications

- Immunogenicity and safety are different

- If studied indication is not sensitive in detecting differences in all aspects of efficacy and safety

The infliximab biosimilar (Remsima) was approved by EMA (European Medicines Agency) for all indications for reference biologic on the basis of submitted clinical data for rheumatoid arthritis and ankylosing spondylitis.

\section{Reference product requirement}

- Must be authorized in European Economic Area (EEA)

- In the case of non-EEA authorized comparator, bridging data comparing all three products including analytical studies with clinical and non-clinical data should be submitted (proposed biosimilar, EEA-authorized reference product and not EEAauthorized comparator).

\section{Interchangeability}

- Interchangeability assessment is left to member states.

- In EU countries, treatment decisions to treat patients is left to the physicians and patients to avoid "automatic substitution."

- France Law (2014) states that a biosimilar may be dispensed only as an initial treatment to a new, or "naive" patient, and only if physician states that prescribed biologic is "nonsubstitutable."

- In the case of substitution, records are maintained by the pharmacists.

\section{European biosimilar marketing authorization summary}

Out of 29 Marketing Authorization Applications (MAA) filed, 21were approved, one was rejected, and seven were withdrawn by the applicant. Out of 21 approved biosimilars, two were voluntarily withdrawn by the applicant (fig. 1).

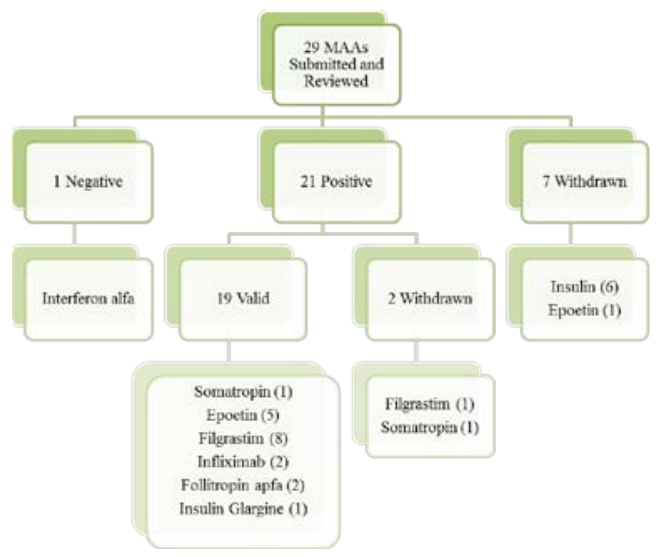

Fig. 1: Market authorization summary of Europe

\section{Brazil-biosimilar regulatory summary $[16,17]$}

\section{Guidelines}

- ANVISA (National Health Surveillance Agency) Guideline on Biosimilar (Board Resolution-RDC No. 55 OF 16 DECEMBER 2010)

Biosimilar regulatory guideline for Brazil was released in 2010 and is based on WHO and EU biosimilar guidelines. Follow-on biological product which is comparable to reference biological with respect to quality, non-clinical and clinical parameters in terms of quality, efficacy, and safety.

\section{Data requirement}

\section{Analytical, quality characterization data}

Biological and physicochemical characterization related to quality attributes, purity, and impurity profile, with discussion of potential impact on quality, safety, and efficacy.

\section{Non-clinical studies data}

- In vitro studies

- In vivo studies: Pharmacodynamics studies and studies of cumulative toxicity (repeat dose) including parameters characterizing kinetics of toxicity

\section{Clinical studies data}

- Phase I: PK and PD studies; can be a combined study (usually 1 or 2 CTs depending on indications)

- Phase III: comparative clinical safety and efficacy pivotal studies (usually 1 or 2 CTs, depending on number of indications and safety profile)

- Post-marketing: Safety and immunogenicity data

\section{Extrapolation to other indication}

- MOA and receptors involved for different indications are same.

- Safety and Immunogenicity are sufficiently characterized.

\section{Reference product requirements}

- Reference product should be registered with ANVISA Brazil.

- Non-Brazil reference product needs to be registered by another regulatory authority which has similar criteria as ANVISA with full unrestricted access to registration information to ANVISA.

\section{Interchangeability}

Not mentioned in the guidelines. 


\section{China-biosimilar regulatory summary [18-20]}

\section{Guidelines}

- Chinese guidance for the development, evaluation, license approval of biosimilars was released in 2015.

Similar therapeutic biological product/biosimilar is similar to an authorized reference product in terms of quality, safety, and efficacy. Biosimilar should contain same active substance as the reference product, and differences such as different host cell and expression system should be justified.

\section{Data requirement}

\section{Analytical, quality characterization data}

- Comparability in production processes, structural and functional characterization, physical and chemical properties, potency, purity.

- Biosimilar drug should have a same amino acid sequence as the reference product.

\section{Non-clinical data}

- In vitro studies
- In vivo studies: PK, PD, immunogenicity assessment, repeat dose toxicity studies and other toxicity studies should be conducted using same models and animal species as the reference product.

\section{Clinical data}

- Phase I: PK and PD study (usually 1 or 2 CTs depending on indications)

- Phase III: Comparative efficacy and safety/immunogenicity study (usually 1 or 2 CTs depending on indications)

- Post-marketing: Risk management plan, safety, and immunogenicity data

\section{Extrapolation to other indication}

Extrapolation of indications possible, which will be considered on a case-by-case basis and product specific based on appropriately selected indications which have been thoroughly studied in clinical trials. Safety and immunogenicity in relation to extrapolated indications should be sufficiently assessed.

Table 1: A comparative summary of data submitted for approval of infliximab biosimilar in India, Brazil, and Europe

\begin{tabular}{|c|c|c|c|}
\hline Country/Data & India & Europe & Brazil \\
\hline Company & $\begin{array}{l}\text { Ranbaxy (sun pharmaceuticals)/Epirus } \\
\text { Biopharmaceuticals }\end{array}$ & Celltrion & Celltrion \\
\hline $\begin{array}{l}\text { Approval Date } \\
\text { Reference } \\
\text { Biologic }\end{array}$ & $\begin{array}{l}\text { Mar } 2014 \text { (approval)/Nov } 2014 \text { (launch) } \\
\text { Remicade/Janssen Biologics }\end{array}$ & 10 Sep 2013 & April 27, 2015 \\
\hline Analytical Data & $\begin{array}{l}\text { Extensive bio-analytical and physicochemical comparison } \\
\text { of infliximab biosimilar and Remicade including full side- } \\
\text { by-side characterization of all Critical Quality Attributes } \\
\text { (CQAs). }\end{array}$ & $\begin{array}{l}\text { An extensive product } \\
\text { characterization exercise } \\
\text { was conducted, to } \\
\text { elucidate: } \\
\text { 1. Primary, secondary and } \\
\text { higher order structure } \\
\text { 2. Post-translational } \\
\text { modifications and } \\
\text { associated micro- } \\
\text { heterogeneity } \\
\text { 3. Glycosylation } \\
\text { 4. Charged isoforms } \\
\text { 5. Purity and biological } \\
\text { activity associated with CT- } \\
\text { P13 (Remsima) }\end{array}$ & $\begin{array}{l}\text { Celltrion submitted same analytical } \\
\text { data related to manufacturing, } \\
\text { quality control, and therapeutic } \\
\text { experimentation report as filed } \\
\text { before European Medicines Agency } \\
\text { (EMA) }\end{array}$ \\
\hline Non-Clinical & In vitro & & \\
\hline \multirow[t]{3}{*}{ Data } & Target binding studies & $\begin{array}{l}33 \text { in vitro studies including } \\
\text { comparative binding } \\
\text { affinity, apoptotic effects, } \\
\text { human tissues cross- } \\
\text { reactivity, etc. }\end{array}$ & Same as filed before EMA \\
\hline & In vivo & & \\
\hline & $\begin{array}{l}\text { 1. Two single dose toxicity in Swiss albino mice and Wistar } \\
\text { rats; } \\
\text { 2. Two repeat dose toxicity in Wistar rats and New Zealand } \\
\text { White Rabbits }\end{array}$ & $\begin{array}{l}\text { 1. Two weeks repeat dose } \\
\text { toxicity studies in rats } \\
\text { 2. One dose range finding } \\
\text { study }\end{array}$ & Same as filed before EMA \\
\hline \multirow[t]{4}{*}{ Clinical Data } & Phase I study & & \\
\hline & $\begin{array}{l}\text { Intravenous dose study (in the United Kingdom) in } 84 \\
\text { healthy volunteers to compare pharmacokinetics, safety, } \\
\text { tolerability and immunogenicity of infliximab biosimilar } \\
\text { (n=43) with Remicade (n=41) with a } 12 \text {-week follow-up } \\
\text { period }\end{array}$ & $\begin{array}{l}\text { 1. } 54 \text { w study: PK at } 22 \text { and } \\
30 \text { w; long-term efficacy, } \\
\text { PK and safety up to } 54 \text { w } \\
2.102 \text { w study: PK at } 0,2 \\
\text { and } 6 \text { w; PD, efficacy, and } \\
\text { safety up to } 102 \text { w }\end{array}$ & Same as filed before EMA \\
\hline & Phase III study & & \\
\hline & $\begin{array}{l}\text { One Phase III randomized, double-blind, active comparator } \\
\text { study (in India) to compare efficacy and safety of infliximab } \\
\text { biosimilar }(n=127) \text { with Remicade }(62) \text { with severe, active } \\
\text { rheumatoid arthritis on stable doses of methotrexate in } \\
189 \text { patients with rheumatoid arthritis taking methotrexate }\end{array}$ & $\begin{array}{l}\text { One comparative } \\
\text { equivalence study of } 54 \mathrm{w} \\
\text { duration } \\
\text { Efficacy at } 30 \text { and } 54 \mathrm{w} \text {; } \\
\text { long-term safety, } \\
\text { immunogenicity up to } 54 \mathrm{w}\end{array}$ & Same as filed before EMA \\
\hline
\end{tabular}




\section{Reference product requirement}

- China FDA approved reference product. Reference product can be pending for cFDA approval during early stages of biosimilar development process, but must be approved by cFDA when comparative clinical studies are conducted.

- Companies cannot use an approved biosimilar as reference drug. Interchangeability

The guideline does not mention any concept of interchangeability (table 1).

\section{CONCLUSION}

The standard generic approach (demonstration of bioequivalence with a reference medicinal product by appropriate bioavailability/ bioequivalence studies) which applies to most chemically-derived medicinal products is in principle not appropriate to biological/biotechnology-derived products due to their complexity. For approval of a biosimilar product, guidelines in various countries provide abbreviated approval pathway involving step-wise comparability exercise of a biosimilar with reference biological product which requires the generation of comparative analytical, non-clinical and clinical data (usually one or two phase I and phase 3 comparative studies). The scientific principles of such a biosimilar comparability exercise are based on those applied for evaluation of the impact of changes in manufacturing process of a biological medicinal product. The amount of data required for biosimilar approval is more than that for generic small molecule chemical product approval and less than that for reference biological product.

Analytical and non-clinical data requirement are similar across countries. Local subject participation is required in local or global phase I and phase III study. Local Phase I studies may be waived off in certain geographies like India and Brazil at the discretion of the regulatory authority. Since local participation is required in all countries, so Phase III trial should be global and multi-centric. There is a need to develop a robust post-marketing surveillance plan to allay safety/immunogenicity concerns.

Reference product used in comparability exercise should be registered in a country where the approval for a biosimilar is sought. However, reference product registered in a different country may be used with bridging data.

Clinical trials can be initiated at any time irrespective of patent expiry. This provision is available in many countries and is similar to BOLAR provision in US [§ 271(e) (1) exemption from infringement if patented reference product is used for generating data for submitting to regulatory agency]. Biosimilar application can be filed after the expiry of regulatory/data exclusivity. However, a biosimilar can only be approved or launched after the expiry of patent and regulatory exclusivity.

By submitting data for one lead indication, approval for other approved indications (extrapolation) of reference product is possible if scientific justification is provided. There is no provision of interchangeability in guidelines of most of the geographies. In EU, no automatic substitution and decision for interchangeability are left to the member country.

\section{CONFLICT OF INTERESTS}

\section{Declared none}

\section{REFERENCES}

1. World Health Organization. Guidelines on evaluation of similar biotherapeutic products (SBPs); 2009. p. 23-30.

2. Markets, markets. Biosimilars Market by Product (Recombinant Non-Glycosylated Proteins (Insulin, Filgrastim, Interferons, rHGH), Glycosylated (Monoclonal Antibodies, EPO), Peptides (Glucagon, Calcitonin)) and Application (Oncology, Blood Disorders)-Global Forecast to 2020. marketsandmarkets.com; 2015. p. 9-12.
3. Kandhare AD, Raygude KS, Ghosh P, Gosavi TP, Bodhankar SL. A comparative cross-sectional descriptive study of individual pharmacy Vs mall pharmacies to evaluate customer satisfaction as well as purchasing behavior. Der Pharm Lett 2011;3:71-83.

4. Calvo B, Zuniga L. The US approach to biosimilars: the longawaited FDA approval pathway. Biol Drugs 2012;26:357-61.

5. Kumar R, Sigala S, Malgarini RB, Pimpinella G, Pani L, Pecorelli $\mathrm{S}$, et al. Biosimilars: regulatory status and implications across the World. J Pharmacovigilance 2015;(S3):2.

6. Berkowitz SA, Engen JR, Mazzeo JR, Jones GB. Analytical tools for characterizing biopharmaceuticals and the implications for biosimilars. Nat Rev Drug Discovery 2012;11:527-40.

7. Socinski MA, Curigliano G, Jacobs I, Gumbiner B, MacDonald J, Thomas D. Clinical considerations for the development of biosimilars in oncology. MAbs 2015;7:286-93.

8. World Health Organization. Expert committee on biological standardization. Geneva, 19 to 23 October 2009. Guidelines on evaluation of similar biotherapeutic products (SBPs). 2009. p. 12-8.

9. Rathore A. Guidelines on similar biologics: regulatory requirements for marketing authorization in India. PDA J Pharm Sci Technol 2011;66:393-3.

10. Ghosh P, Kandhare AD, Kumar VS, Rajmane AR, Adil M, Bodhankar SL. Determination of clinical outcome and pharmacoeconomics of anti-rheumatoid arthritis therapy using CDAI, EQ-5D-3L and EQ-VAS as indices of disease amelioration. Asian Pac J Trop Dis 2012;2:S671-S678.

11. Sarkate AP, Murumkar PR, Lokwani DK, Kandhare AD, Bodhankar SL, et al. Design of selective TACE inhibitors using molecular docking studies: Synthesis and preliminary evaluation of anti-inflammatory and TACE inhibitory activity. SAR QSAR Environ Res 2015;26:905-23.

12. Bhilare NV, Dhaneshwar SS, Sinha AJ, Kandhare AD, Bodhankar SL. Novel thioester prodrug of N-acetylcysteine for odor masking and bioavailability enhancement. Curr Drug Delivery 2016;13:611-20.

13. Goswami S, Kandhare AD, Zanwar AA, Hegde MV, Bodhankar $\mathrm{SL}$, Shinde S, et al. Oral L-glutamine administration attenuated cutaneous wound healing in Wistar rats. Int Wound J 2016;13:116-24.

14. Kandhare AD, Alam J, Patil MV, Sinha A, Bodhankar SL. Wound healing potential of naringin ointment formulation via regulating the expression of inflammatory, apoptotic and growth mediators in experimental rats. Pharm Biol 2016;54:419-32.

15. Kandhare AD, Bodhankar SL, Mohan V, Thakurdesai PA. Effect of glycosides based standardized fenugreek seed extract in bleomycin-induced pulmonary fibrosis in rats: decisive role of Bax, Nrf2, NF-kappaB, Muc5ac, TNF-alpha, and IL-1beta. Chem Biol Interact 2015;237:151-65.

16. Kandhare AD, Raygude KS, Ghosh P, Gosavi TP, Bodhankar SL. Patentability of animal models: India and the globe. Int J Pharm Biomed Res 2011;2:1024-32.

17. Ghosh P, Kandhare AD, Gauba D, Raygude KS, Bodhankar SL. Determination of efficacy, adverse drug reactions and cost effectiveness of three triple drug regimens for the treatment of Helicobacter pylori infected acid peptic disease patients. Asian Pac J Trop Dis 2012;2:S783-S789.

18. Ghosh P, Kandhare AD, Raygude KS, Gauba D, Gosavi TP, Bodhankar SL. Cigarette smoking and H. pylori infection: a meta-analysis of the literature. Der Pharm Lett 2012;4:128-34.

19. Raygude K, Kandhare A, Ghosh P, Gosavi T, Bodhankar S. Consumption of alcohol and H. pylori infection: A cumulative meta-analysis of the literature. Asian J Biochem Pharm Res 2011;3:338-45.

20. Visnagri A, Kandhare AD, Chakravarty S, Ghosh P, Bodhankar SL. Hesperidin, a flavanol glycone attenuates experimental diabetic neuropathy via modulation of cellular and biochemical marker to improve nerve functions. Pharm Biol 2014;52:814-28.

\section{How to cite this article}

- Meenakshi K Chauhan, Shipra Malik. Regulatory guidelines for approval of biosimilars in India, Europe, Brazil and China: a comprehensive overview. Int J Pharm Pharm Sci 2016;8(10):7-11 